\title{
BMJ Open Impact of China's healthcare price reforms on traditional Chinese medicine public hospitals in Beijing: an interrupted time-series study
}

Dawei Zhu, ${ }^{1}$ Xuefeng Shi, ${ }^{2}$ Stephen Nicholas, ${ }^{3,4,5,6}$ Qian Bai, ${ }^{2}$ Ping He ${ }^{1}$

To cite: Zhu D, Shi X, Nicholas S, et al. Impact of China's healthcare price reforms on traditional Chinese medicine public hospitals in Beijing: an interrupted time-series study. BMJ Open 2019;9:e029646. doi:10.1136/ bmjopen-2019-029646

- Prepublication history and additional material for this paper are available online. To view these files, please visit the journal online (http://dx.doi org/10.1136/bmjopen-2019029646).

DZ and XS contributed equally.

Received 03 February 2019

Revised 05 July 2019

Accepted 12 July 2019
Check for updates

(C) Author(s) (or their employer(s)) 2019. Re-use permitted under CC BY-NC. No commercial re-use. See rights and permissions. Published by BMJ.

For numbered affiliations see end of article.

Correspondence to

Dr Ping He; phe@pku.edu.cn

\section{ABSTRACT}

Objective To evaluate the 2017 implementation of China's 2009 healthcare price reforms on Beijing's secondary and tertiary traditional Chinese medicine (TCM) hospitals.

Design We employed a panel-interrupted time-series model with hospital fixed effects to estimate the impact of the price reforms.

Setting Beijing, April 2014 to April 2018.

Participants All TCM hospitals in Beijing.

Outcome measures Our dependent variables comprised the monthly outpatient and inpatient revenues, the number of monthly outpatient visits and inpatient admissions, the average total expenditures per outpatient visit and per inpatient admission, the average drug expenditures (except herbal medicines) per outpatient visit and per inpatient admission and the average medical service expenditures per outpatient visit and per inpatient admission.

Results In tertiary hospitals, the price reforms led to significant reductions in the number of outpatient visits (23.1\%), inpatients admission (4.6\%) and drug expenditures (except herbal medicines) per inpatient admission (14.0\%), and an instant raise in average total expenditure per outpatient (22.0\%), medical service expenditures per outpatient visit (58.2\%) and inpatient admission (19.0\%). There was no significant association between the price reforms and the monthly outpatient and inpatient revenues. After the price reforms, the previous upward trend in medical service expenditures per outpatient visit rose more sharply (from $0.5 \%$ to $1.6 \%$ ). In secondary hospitals, the price reforms decreased the level of drug expenditures (except herbal medicines) per outpatient visit (13.0\%) and per inpatient admission (20.8\%), but increased medical service expenditures per inpatient admission by $19.0 \%$.

Conclusion The Beijing price reforms adjusted the cost structures in secondary and tertiary TCM hospitals without negatively impacting the operation of the hospitals, and through the increased hierarchical medical service fee, shifted patient choices away from tertiary to other health facilities, especially for patients with minor illnesses.

\section{INTRODUCTION}

With Chinese households facing an unsustainable health spending burden and an underfunded health system, China's 2009 health policy reform package aimed to provide

\section{Strengths and limitations of this study}

- Using all Beijing traditional Chinese medicine (TCM) public hospitals, we conducted a panel-interrupted time-series design to examine the effects of the implementation of China's 2009 price reforms on Beijing's TCM hospitals.

We examined both short-run and long-run effects on different levels of TCM hospitals.

- Our sample included TCM hospitals only, and our results may be not applied to non-TCM hospitals.

households secure, efficient, convenient and affordable healthcare services by reversing the early 1980s move to a market-oriented health system. ${ }^{1}$ Price regulations, which distorted healthcare incentives for physicians, hospitals and patients, and low government health spending were identified as key reform issues along with urban-rural and regional inequalities in health provision; irrational resource allocation; weak public and community health provision; incomplete medical insurance and imperfect hospital management systems. ${ }^{1-3}$ Beginning in 2009, the reforms were progressively piloted across China at community health centres (2009), county public hospitals (2012) and urban public hospitals (2015). ${ }^{4}$ In April 2017, Beijing implemented the 2009 healthcare reforms in all public comprehensive and traditional Chinese medicine (TCM) health facilities. The aim of the Beijing's price reforms was to change the incentives of public hospitals and physicians, address the distorted service and drug cost structure, reduce inflated healthcare expenditures and shape the tiered healthcare delivery system. ${ }^{5}$ Did the price reforms in Beijing's TCM hospitals achieve these aims?

In the pre-2009 health reform period, the main feature of price regulation was to set prices for basic health services, especially for services with large labour inputs, far below 
costs, while setting prices for high-tech diagnostic tests far above costs and to allow hospitals and doctors to add a $15 \%$ mark-up on drug sales. ${ }^{23}{ }^{36-8}$ The intention of these price regulations was to keep basic health services affordable, especially for poor farmers, ensuring widespread access. ${ }^{23}$ With falling government subsidies to hospitals, the $15 \%$ drug sale mark-up and higher prices on hightech diagnostic test were used to cross-subsidise losses on basic services and to keep health facilities financially viable. ${ }^{2}$ The pre-2009 price schedule resulted in distorted supply-side and demand-side incentives, and accelerated the growth of health expenditures. ${ }^{26}$ At the same time, the government from the mid-1980s adopted a cost recovery policy in hospital financing and decreased subsidies from roughly $60 \%$ of total hospital income to only $11 \%$ in $2009 .^{9}$ By 2009 , hospitals earned roughly $90 \%$ of their budget from revenue-generating activities. Further, a bonus system rewarded physicians based on the monetary values of drugs they prescribed. The self-funding financial pressures and the doctor bonus system incentivised physicians to generate revenues for the hospital and themselves by overprescribing drugs and conducting excessive diagnostic tests. ${ }^{2} 810$

These cost pressures were exacerbated by Chinese patients' preference, including those with minor illnesses, to access tertiary hospitals directly, rather than seek attention from primary healthcare facilities. In China, healthcare is delivered via a three-tiered system, comprising village clinics, township and county hospitals in rural areas, and community health centres, district hospitals and municipal hospitals in urban areas. ${ }^{11} 12$ All three levels offer both western and TCM healthcare. ${ }^{13}$ Primary care facilities, including village clinics, township hospitals and community health centres, provide preventive and primary care services. ${ }^{12}$ County and district hospitals, with 100-499 beds, are usually secondary hospitals providing basic specialty care and inpatient services. ${ }^{14}$ With over 500 beds, municipal hospitals are large-scale city-based tertiary hospitals, providing complex healthcare. With patients permitted to choose their initial health facility for treatment without referral, patient's preference for accessing tertiary hospitals was reinforced by the small price gaps between the three different levels of healthcare, with the outpatient registration and consultation fee for an attending physician Y3.5 in primary, Y4 in secondary and $\mathrm{Y} 5$ in tertiary hospitals. ${ }^{15} 16$ The combined demand and supply effects, and patient healthcare preferences for tertiary hospitals, saw total healthcare expenditure triple from Y1095 per capita in 2008 to Y3352 per capita in 2016, an annual growth rate of $15 \%$, which was almost twice the growth rate of GDP. ${ }^{17}$

New price regulations in the 2009 health reforms sought to change the distorted incentives of the pre-2009 pricing system. ${ }^{18} 19$ As a key part of the new health system reforms, the zero-mark-up drug policy (ZMDP) ended the previously permitted $15 \%$ profit margin for drug sales. ${ }^{18}{ }^{19}$ Healthcare price reform was the key part of Beijing health system reform. ${ }^{20}$ In Beijing's price reforms, mark-ups on non-herbal medicine sales were disallowed, the price for high-tech diagnostic tests, such as CT and nuclear magnetic resonance, were decreased and the price for health services which involve more skill and labour-intensive input was increased. Another important part of the Beijing's price reforms was setting hierarchical medical service fees to replace the registration and consultation fee, which were paid upfront before each physician visit. The hierarchical medical service fee indirectly increased the 'admission price' to medical treatment, especially for patients not covered by Beijing's health insurance scheme, such as the floating, mainly rural, migrant population. The Beijing pre-2017 outpatient registration and consultation fee for an attending physician was increased from Y3.5 to Y20 in primary, from $\mathrm{Y} 4$ to $\mathrm{Y} 30$ in secondary and from $\mathrm{Y} 5$ to $\mathrm{Y} 50$ in tertiary hospitals. Out-of-pocket expenditures were reimbursed by the Beijing health insurance scheme at a rate of $\mathrm{Y} 1$ for primary, Y2 for secondary and Y10 for tertiary hospitals. The effect of the price regulations was to sharply increase the price gaps between different levels of hospital and physician services. Before the 2017 reform, the Beijing price gap was Y1.5 between primary health facilities and tertiary hospitals, and Y4 between attending and chief physicians. In 2017, the gap was Y30 between primary health facilities and tertiary hospitals, and Y40 between attending and chief physicians.

Since its launch in 2017, Beijing's health reforms have attracted extensive nationwide attention. However, there have been few empirical studies examining the effects of the price reforms in Beijing's hospitals. Partial studies, mainly conducted in one hospital or focusing on one aspect of the reforms, such as health expenditure or volume, have been undertaken, ${ }^{21-24}$ but not a comprehensive impact study of Beijing's 2017 health price reforms on secondary and tertiary hospitals. To fill this gap, we conducted a panel-interrupted time-series model with monthly data on medical expenditures and inpatient and outpatient use of all Beijing public secondary and tertiary TCM hospitals from 2014 to 2018.

\section{METHODS}

\section{Patient and public involvement}

Patients or the public were not involved in the design or in the conduct of the study.

\section{Data sources}

To evaluate the impact of healthcare price reform on all public TCM Beijing hospitals (including ethnic minority medicine hospitals and integrated Chinese and Western medicine hospitals), we collected hospital-based monthly data between April 2014 and April 2018 from the Beijing Administration of Traditional Chinese Medicine. In total, we included 1571 hospital-months (1135 hospital-months pre-reform and 436 hospital-months post-reform) to establish unbalanced 
panel data for analysis. Our data cover a 3-year period before and 1-year period after the 2017 implementation of the 2009 heath reforms in Beijing. The data include information on human resources, hospital scale, annual revenues and volume of outpatient and inpatient services.

\section{Outcome measures}

Given the goals of Beijing's healthcare price reforms, and following previous studies, our dependent variables comprised the monthly outpatient and inpatient revenues, the number of monthly outpatient visits and inpatient admissions, the average total expenditures per outpatient visit, the average total expenditures per inpatient admission, the average drug expenditures (except herbal medicines) per outpatient visit, the average drug expenditures (except herbal medicines) per inpatient admission, the average medical service expenditures per outpatient visit and the average medical service expenditures per inpatient admission. ${ }^{19} 25$ The average medical services expenditure per outpatient (inpatient) visit was the average total expenditures per outpatient (inpatient) visit minus the average drug expenditures per outpatient (inpatient) visit. ${ }^{17}$ We expect that the price reforms should reduce the volume of outpatient visits and inpatient admissions at TCM tertiary and secondary hospitals, with a greater fall at tertiary than secondary hospitals, given the higher admission price to medical services at tertiary hospitals. With the termination of the $15 \%$ drug mark-up, drug expenditures (except herbal medicines) should decrease at least $15 \%$. The offsetting expenditures on medical care expenditures are difficult to predict given the changing prices for medical services and diagnostic tests and medical consumables, but the rate of increase in medical service and total expenditures should be reduced.

\section{Study design and statistical analysis}

We used the interrupted time-series design to evaluate changes in outcome variables attributable to the policy changes by comparing outcomes after the 2009 policy implementation in 2017 with estimated outcomes based only on the pre-2017 policy levels and trends or the counterfactual of what post-2017 expenditures would have been if there had been no reform. ${ }^{26} 27$ We used segmented regression models with hospital fixed effects to assess the different impacts on tertiary and secondary hospitals. ${ }^{28} 29$ The two segments were divided by intervention points. The model is specified as follows:

$$
\begin{aligned}
\mathrm{Y}_{\mathrm{it}} & =\beta_{0}+\beta_{1} * \text { secondary }_{\mathrm{it}} * \text { time }_{\mathrm{t}}+\beta_{2} * \text { secondary }_{\mathrm{it}} \\
& * \text { Policy }_{\mathrm{t}}+\beta_{3} * \text { secondary }_{\mathrm{it}} * \text { time after }_{\text {policy }}+\beta_{4} \\
& * \text { tertiary }_{\mathrm{it}}+\beta_{5} * \text { tertiary }_{\mathrm{it}} * \text { time }_{\mathrm{t}}+\beta_{6} * \text { tertiary }_{\mathrm{it}} \\
& * \text { Policy }_{\mathrm{t}}+\beta_{7} * \text { tertiary }_{\mathrm{it}} * \text { time after policy }_{\mathrm{t}}+\alpha \\
& * \mathrm{X}_{\mathrm{it}}+\mu_{\mathrm{i}}+\varepsilon_{\mathrm{it}}
\end{aligned}
$$

where $Y_{i t}$ represents the outcome variables in hospital (i) and month (t); secondary it $_{\text {it }}$ and tertiary ${ }_{\text {it }}$ are two indicator variables to denote the secondary and tertiary hospitals; time ${ }_{\mathrm{t}}$ is a linear time variable, with a value of 1 starting in April 2014, to estimate the baseline trend; Policy ${ }_{\mathrm{t}}$ is a binary indicator for all post-2017 policy months to estimate the immediate-level change in the outcome measure following the policy change; time after policy is a continuous variable counting the number of months after policy implementation, which was set at 0 before the policy change, to estimate the change in trend (slope) during the post-2017 policy period; $\mathrm{X}_{\mathrm{it}}$ are control variables including number of medical staff and hospital beds; $\mu_{i}$ are hospital's individual fixed effects which control for mean differences across hospital; $\varepsilon_{i t}$ refers to the error term. Logarithmic transformations were performed on all outcome variables to adjust for right-skewed data, and coefficients are routinely interpreted in terms of percent change. $^{30}$

For secondary hospitals, we estimated parameters representing the baseline level, $\beta_{0}$, the baseline time trend, $\beta_{1}$, the change in the level of the outcome immediately after the implementation, $\beta_{2}$, and the change in the trend in the outcome after implementation, $\beta_{3}$, with $\beta_{4}-\beta_{7}$ representing these coefficients in tertiary hospitals. We used Fourier terms (pairs of sine and cosine functions) to control for seasonality and other long-term trends. ${ }^{2631} \mathrm{In}$ addition, we used Huber-White SEs clustered at the hospitals level throughout to control for serial correlation in hospital level. ${ }^{32-34} \mathrm{~A} p$ value $<0.05$ was considered statistically significant. Stata V.14 for Windows (Stata Corp, College Station, Texas, USA) was used for the statistical analysis.

\section{RESULTS}

\section{Summary statistics}

The number of Beijing public secondary and tertiary TCM hospitals increased from 30 in 2014 to 34 in 2018. Table 1 summarises the descriptive results for TCM public hospitals in Beijing by period and hospital level. Table 1 shows that there was a large difference between secondary and tertiary TCM hospitals in scale and volume of service. Tertiary hospitals have more than two times the number of health professionals and outpatient volume compared with secondary hospitals, and more than three times the number of hospital beds and inpatient volume compared with secondary hospitals. However, in terms of healthcare price, the difference was relatively small. There were significant differences between pre and post reform values in table 1 in almost all variables, except monthly revenues of outpatient, the number of health professionals and hospital beds.

\section{Monthly outpatient and inpatient revenue}

As shown in figure 1, monthly revenue of outpatient and inpatient services for tertiary hospitals and the monthly revenue for inpatient services in secondary hospitals 


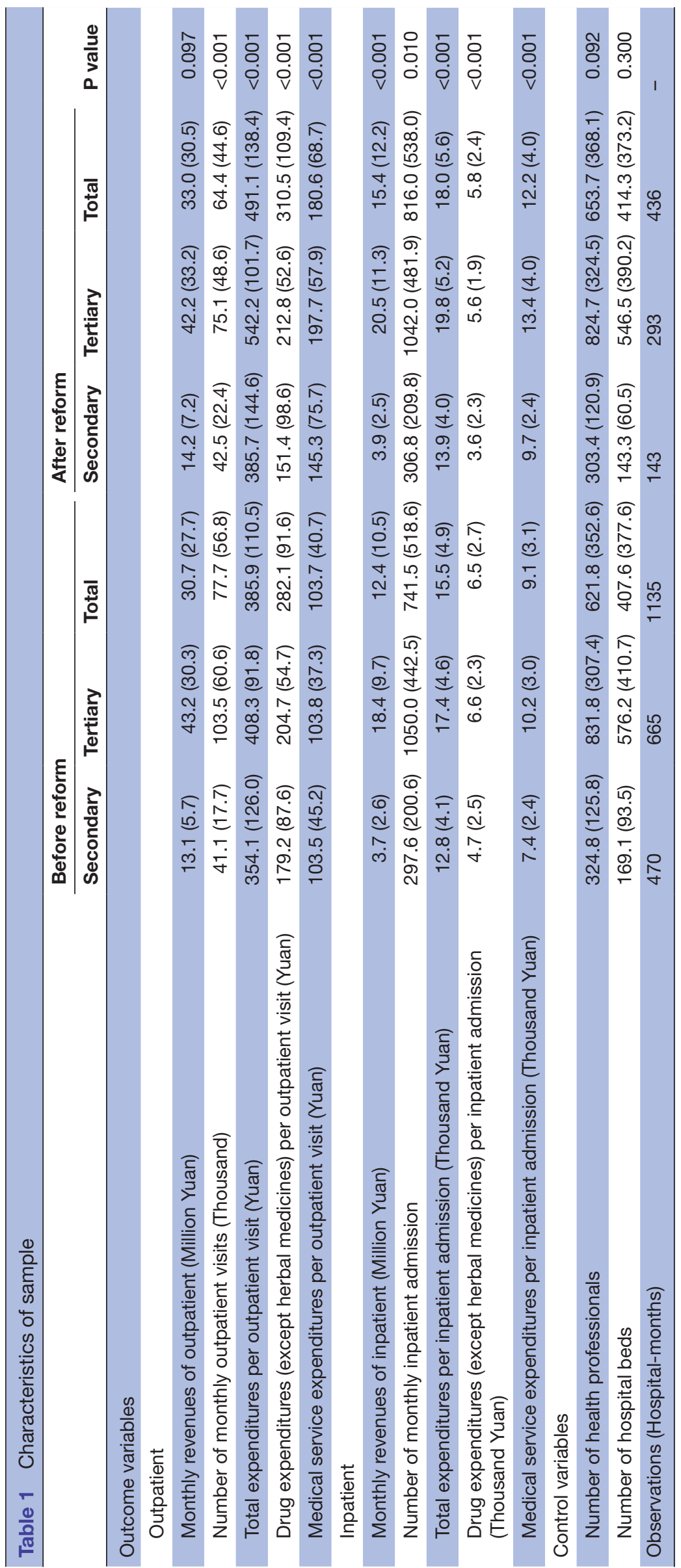



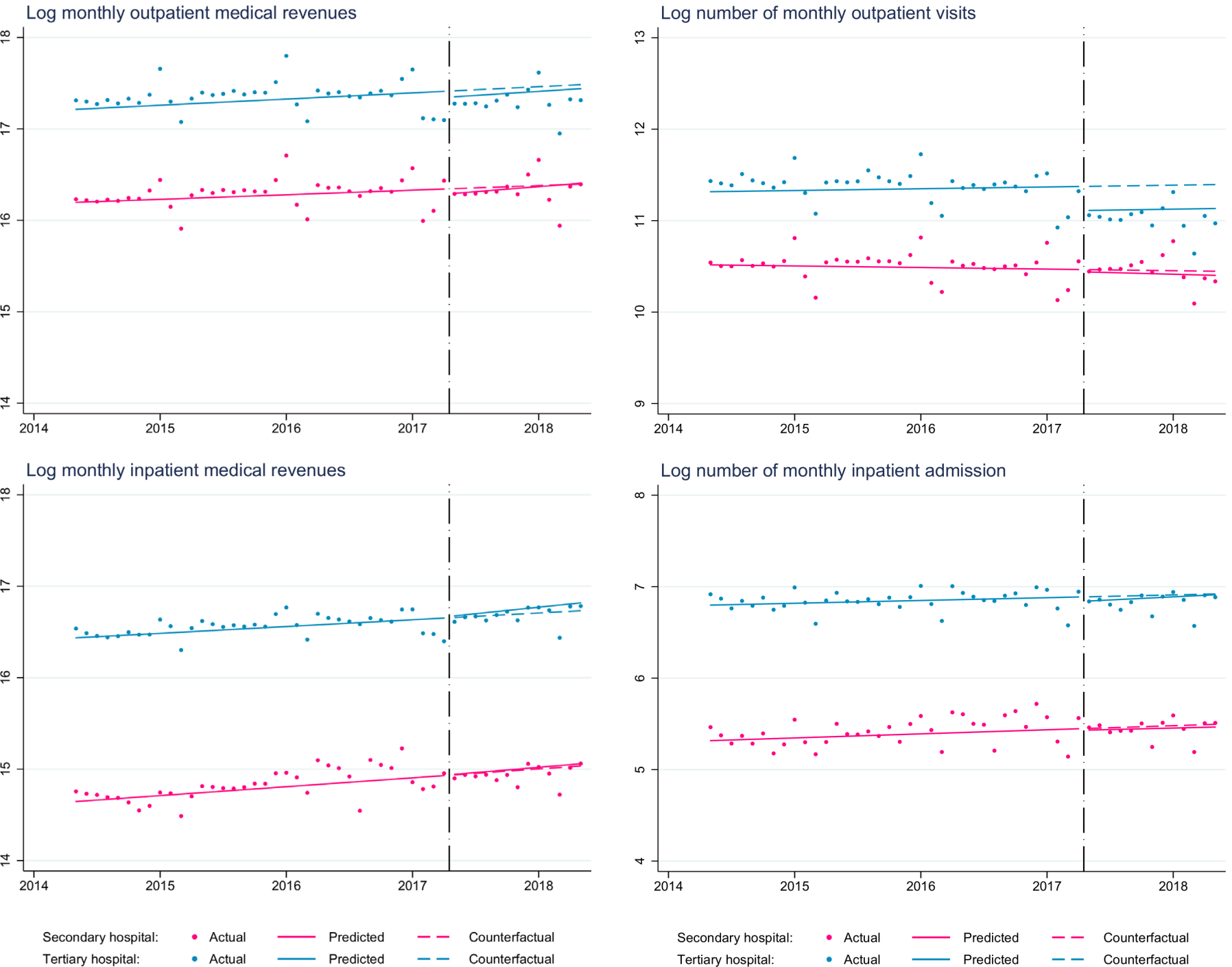

Figure 1 Trend in the monthly medical revenue for TCM public hospitals in Beijing. TCM, traditional Chinese medicine.

exhibited rising trends before the policy implementation in 2017. We did not find any significant change in levels and slopes after the implementation of the price reforms. However, for secondary hospitals, the previous upward trend of monthly inpatient revenue became insignificant while the insignificant upwards trend of monthly outpatient revenue became significant. The numerical details of the levels and slope changes related to price reform are shown in online supplementary table 1.

\section{Monthly volume of outpatient and inpatient service}

Figure 2 shows the different effects of price reform on secondary and tertiary TCM hospitals in terms of the volume of outpatients and inpatients, and the corresponding regression results are presented in online supplementary table 2. Before the reform, both outpatient and inpatient volumes exhibited a stable trend. The price reforms had no significant impact on secondary hospitals' volume of service in both levels and slopes. For tertiary hospitals, there was an immediate $23.1 \%$

Figure 2 Trend in the monthly volume of outpatient and inpatient for TCM public hospitals in Beijing. TCM, traditional Chinese medicine.

$\left(=1-\exp ^{-0.263}, \mathrm{p}<0.001\right)$ drop in the number of monthly outpatient visits and a $4.6 \%\left(=1-\exp ^{-0.047}, \mathrm{p}=0.004\right)$ drop in inpatient admission. However, the reforms did not show any significant impact on the slopes of outpatient and inpatient volume in tertiary hospitals.

\section{Average total health expenditure per outpatient visit and inpatient admission}

The impact of the price reforms on outpatient and inpatient average per capita total health expenditures are displayed in figure 3, and the corresponding regression results are presented in online supplementary table 3 . Significantly increasing trends in outpatient average total expenses were observed for both secondary and tertiary TCM hospitals before the introduction of price reform, as well as for inpatient services in secondary hospitals. Immediately after the implementation of the price reforms, we found a rise of $22.0 \%\left(=\exp ^{0.199}-1, \mathrm{p}<0.001\right)$ in outpatient average total health expenditures for tertiary hospitals, but no significant impact on other outcomes. 

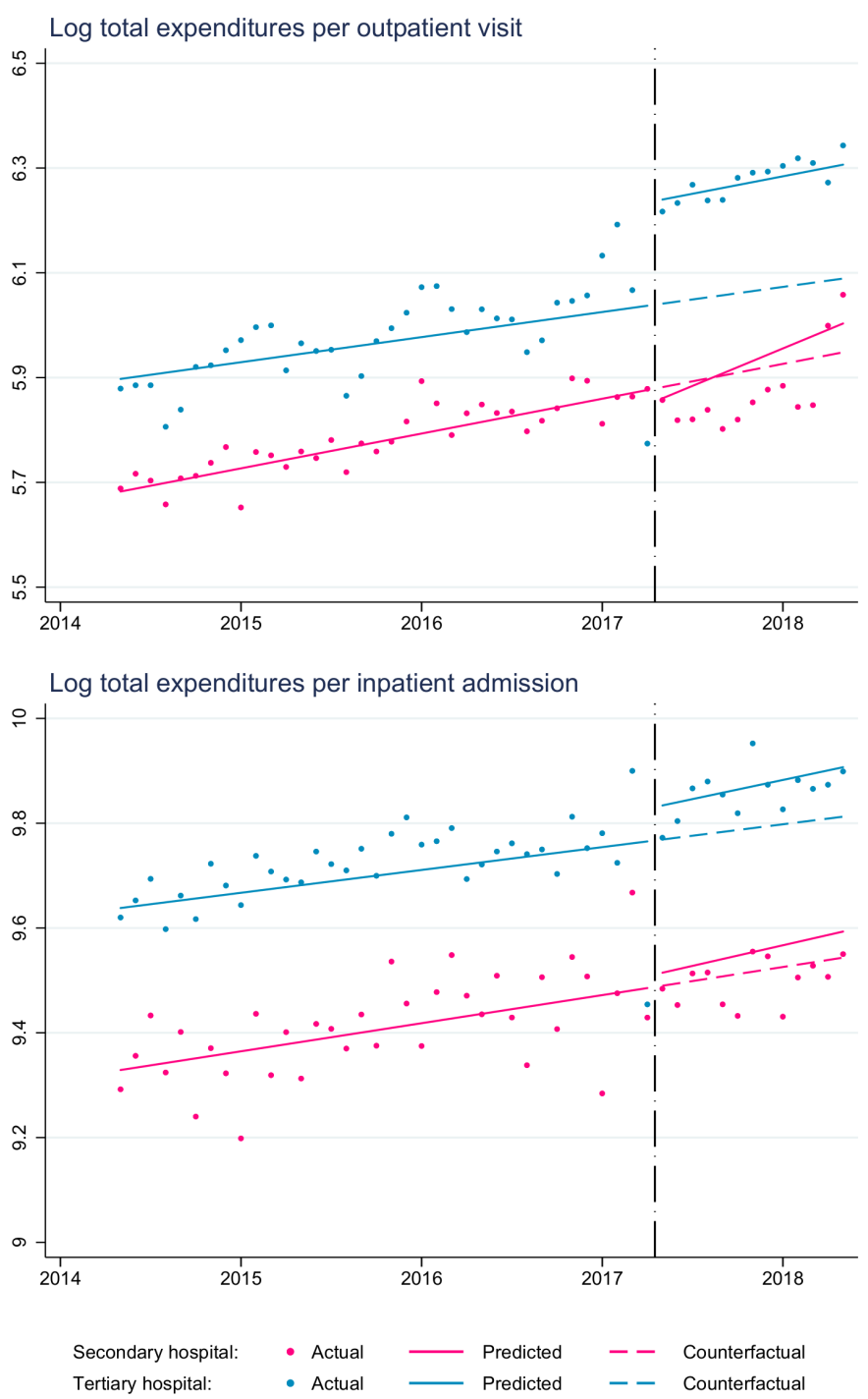

Figure 3 Trend in average total health expenditure in outpatient and inpatient for TCM public hospitals in Beijing. TCM, traditional Chinese medicine.

\section{Average drug and medical service expenditure}

Figure 4 shows the impact of price reforms on cost structure for secondary and tertiary TCM hospitals. The numerical details of regression results are presented in online supplementary table 4. Medical service expenditures per outpatient visit and inpatient admission exhibited rising trends before the policy implementation in 2017. The launch of the price reforms led to significant, and immediate, reduction in the levels of secondary hospitals' drug expenditure (except herbal medicines) per outpatient visit $\left(13.0 \%=1-\exp ^{-0.139}, \mathrm{p}=0.035\right)$ and inpatient admission $\left(20.8 \%=1-\exp ^{-0.233}, \mathrm{p}<0.001\right)$, and in tertiary hospitals' drug expenditure (except herbal medicines) per inpatient admission $\left(14.0 \%=1-\exp ^{-0.151}, \mathrm{p}=0.005\right)$. There was also an immediate rise of $58.2 \%\left(=\exp ^{0.459}-1\right.$, $\mathrm{p}<0.001)$ in tertiary hospitals' average outpatient medical service expenditures per visit, and an immediate rise of $19.0 \%\left(=\exp ^{0.174}-1, \mathrm{p}=0.002\right)$ in both secondary and tertiary hospitals' average medical service expenditures per inpatient admission. There was a significant change in the slope of tertiary hospitals' average outpatient medical service expenditures per visit $(0.5 \%-1.6 \%)$.

\section{DISCUSSION}

To control the rapid growth of healthcare expenditures, to address the distorted cost structure and to shape the tiered healthcare delivery system, the Beijing government removed the $15 \%$ mark-up on drug sales, adjusted prices for 435 medical services, and set hierarchical medical service fees in all public health facilities. Using a panel-interrupted time-series model with hospital fixed effects, this study assessed the impacts of these price reforms on tertiary and secondary public TCM hospitals. As expected, the price reform impacted outpatient and inpatient volume and outpatient average total health expenditure in tertiary TCM hospitals, and the cost structure in both secondary and tertiary TCM hospitals, but we did not find it has significant impact on monthly outpatient and inpatient revenues.

While the monthly outpatient and inpatient revenues remain stable in both secondary and tertiary TCM hospitals, the reason behind this phenomenon was different for each type of hospital. In secondary TCM hospitals, both the medical service volume and the average total health expenditure per outpatient and inpatient admission remained stable. This is consistent with a recent study of county-level hospitals, which is mainly composed of secondary hospitals. ${ }^{19}{ }^{23}$ Stable medical service volumes and average total health expenditure per outpatient and inpatient admission are explained by the increased health services revenue offsetting the income loss by removing mark-ups on drug sales and decreasing the price of diagnostic test. The new medical fee structure induced a shift away from tertiary hospitals by patients, especially those with minor illnesses, to other healthcare facilities, including secondary hospitals.

In tertiary TCM hospitals, the average total health expenditure per outpatient visit increased $22.0 \%$ and inpatient expenditures increased $6.7 \% \quad\left(=\exp ^{0.065}-1\right.$, $\mathrm{p}=0.199$ ), while outpatient volumes fell $23.1 \%$ and inpatient volumes fell by $4.6 \%$. Although the role of tertiary hospitals was to provide complex care, pre-2017 patients usually sought even basic care at tertiary facilities due to the poor quality of the primary care system and the small price gap between higher and lower level health facilities. ${ }^{18}$ The 2017 hierarchical medical service fee increased the 'admission price' to high-level hospitals and specialists, especially for Beijing's floating population. Access to reimbursements from China's national health insurance schemes was based on a person's local hukou household registration, which meant Beijing's trans-provincial floating population met a higher 'admission price' than Beijing's local hukou patients. Previous studies have estimated a relatively high elasticity of demand for specialists visits ${ }^{35}$ so the increased 'admission price' decreased the utilisation of high-level medical service among patients with minor illness, poor patients unable to pay for 


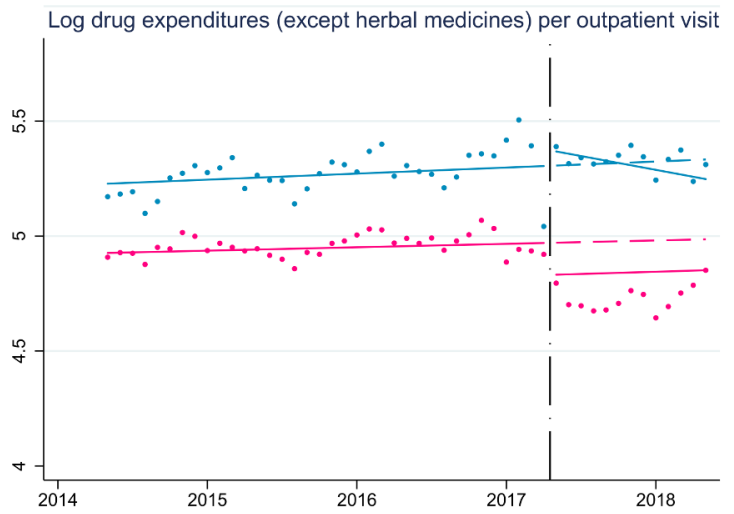

Log drug expenditures (except herbal medicines) per inpatient admission
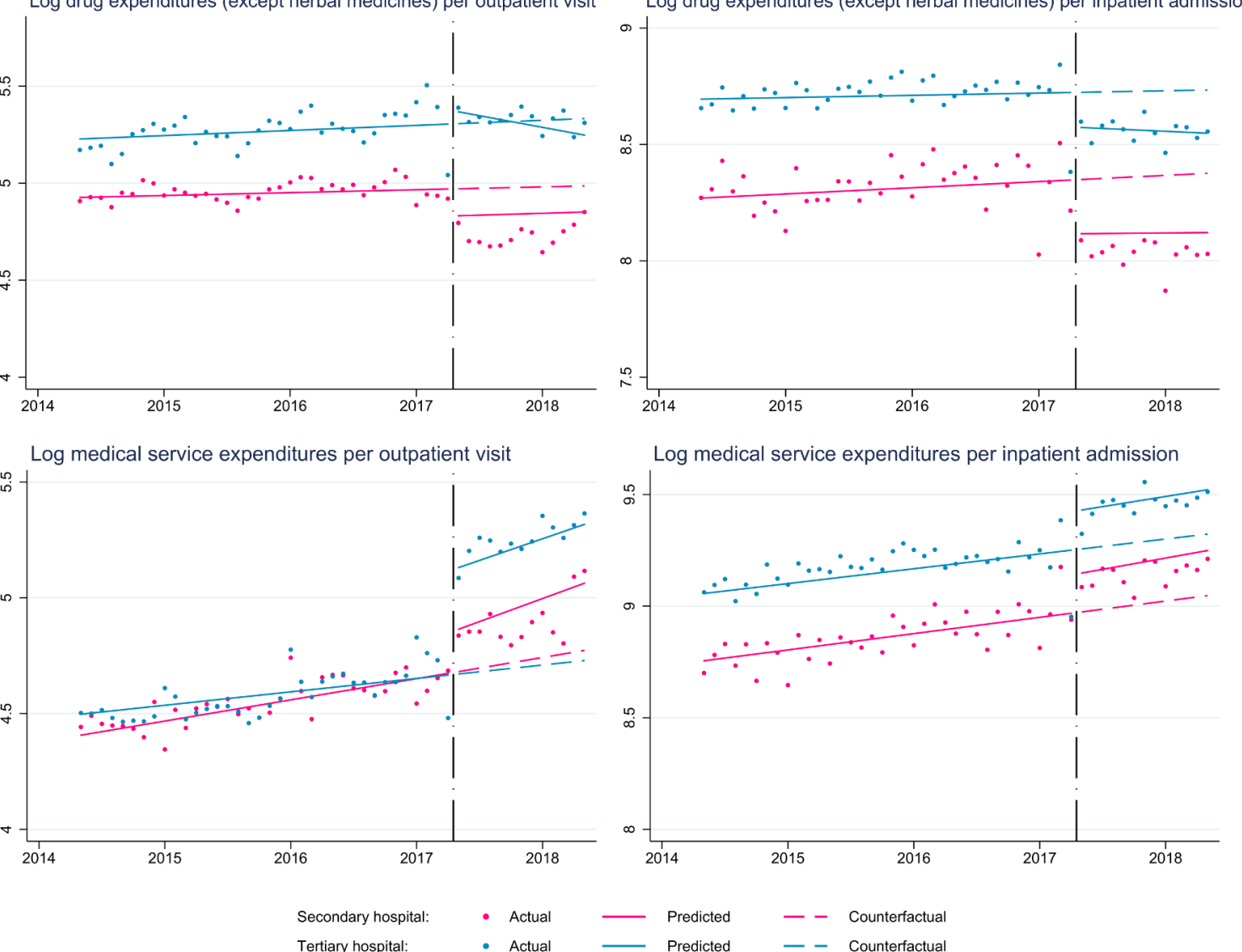

medical expenses and patients without access to health insurance. Fewer patients accessed tertiary hospitals. Due to the nature of our data, we cannot determine whether patients reduced their utilisation of health services or moved to primary health facilities or secondary hospitals. We expect that both effects occurred, especially given the stable inpatient and outpatient revenues at secondary hospitals. Clearly, the effect of the policy changes was to reduce patient access to tertiary hospitals. We also postulate that the price changes increased the proportion of more seriously ill patients, and reduced the proportion of non-serious ill patients, in tertiary hospitals, which resulted in higher expenditures due to the medical fee price increases and more diagnostic testing, which increased the average total expenditures per tertiary hospital outpatient visit and inpatient admission.

Another purpose of the price reforms was to change the distorted cost structure by realigning the incentives of physicians and hospitals. The reforms were intended to reduce physicians' incentives to overprescribe by removing the profit margins for drug sales, and to increase medical service revenue by increasing the prices for medical services. If physicians' post-price reform behaviour remained unchanged, drug expenditure (except herbal medicines) would decrease by $15 \%$ due to the removal of $15 \%$ mark-up on drug sales. The drop in drug expenditures (except herbal medicines) was larger in secondary than in tertiary TCM hospitals and in inpatient services than in outpatient services. For secondary TCM hospitals, reductions of $13.0 \%$ for outpatient and $20.8 \%$ for inpatient services confirm that the price reforms significantly changed physicians' prescription behaviours. The immediate raise of $6.3 \%\left(=\exp ^{0.061}-1, \mathrm{p}=0.216\right)$ for outpatient services in tertiary TCM hospitals was more modest than the $15 \%$ drop in mark-ups, which implies that even larger quantities of drugs and/or more expensive drugs were prescribed after the price reform implementation in 2017, especially for outpatient services, in tertiary hospitals. A recent study in a single tertiary hospital by Yi-zhang et al found similar results. ${ }^{22}$

There are a number of possible explanations for the $<15 \%$ mark-up fall in tertiary TCM hospital drug expenditures (except herbal medicines). Given the same budget, the reduction in the prices of drugs meant that patients bought more drugs or more expensive drugs, especially in tertiary hospitals, which have higher availability of drugs than other hospitals. ${ }^{36}$ The mix of patients changed, with more seriously ill patients attending tertiary hospitals and inpatient services, requiring higher quantities, or more expensive, drugs. Although the price reforms removed the profit for drug sales at hospital level, physicians still had an incentive and ability to overprescribe drugs since they may receive kickbacks from pharmaceuticals companies. Overprescribing may have been more 
likely in tertiary hospitals which had more chief physicians. ${ }^{18}$ Finally, patients frequently 'demand' drugs from physicians, and patient-led demand for prescriptions, especially for outpatients, may have led to higher drug prescriptions.

We can also explain the rising medical service expenditures from both the demand and supply side. On the demand side, the decreased price of diagnostic tests will increase the demand by patients for high-tech diagnostic test. On the supply side, according to the standard model of physician behaviour, physicians may increase the volume and intensity of services with higher price-cost margins to compensate for revenue losses from the new price regulations. ${ }^{37}$ Even when the price of diagnostic test was decreased, physicians still make profit since the test price was still higher than its cost. In addition, the increased price for health services that involved both higher skilled and more intensive labour input also accelerated the rising medical care service expenditures. Notably, there was an increase in the trend of medical care service expenditures per outpatient visiting tertiary TCM hospitals. This can be explained by the increase in the proportion of seriously ill patients in tertiary TCM hospitals after reform and the decrease in patients more appropriately served by primary health facilities after the new pricing regulations. However, additional measures need to be taken to control the rapid growth of outpatient medical care service expenditures in tertiary TCM hospitals.

There are several limitations to this study. Since our sample only included TCM hospitals, our results may not apply to non-TCM hospitals. For example, TCM hospitals might experience a greater loss of drug revenue due to greater reliance on drug sales before reform than non-TCM hospitals. Second, we cannot test whether patients reduced their utilisation of health services or moved to primary health facilities. Even if patients simply moved from TCM hospitals to primary health facilities, the accessing of primary health facilities by patients who should not have been using TCM hospitals reflected a better allocation of health resources. Third, our data do not allow us to examine the effect of the price reforms on volume of high-tech diagnostic test and health services, which involve more skilled and labor-intensive inputs. Despite these limitations, the strengths of our study include panel-interrupted time-series design using all TCM public hospitals, considering both short-run and long-run effect on different levels of hospitals.

\section{CONCLUSION}

Using a panel-interrupted time-series model, we estimated the impact of the 2017 price reform on all Beijing's TCM public hospitals. Our findings show that the price changes of drug, diagnostic test and health services adjusted the cost structures in secondary and tertiary TCM hospitals without negatively impacting the operation of the hospitals. The increased hierarchical medical service fee shifted patient choices away from tertiary to other health facilities or no health services, especially for patients with minor illnesses, poor patients and trans-province patients without Beijing health insurance. Overall, the Beijing's price reforms achieved their goals in Beijing TCM hospitals. Additional work is needed to see whether patients reduced their utilisation of health services or moved to secondary and primary health facilities. To address the acceleration in the growth of outpatient medical services expenditures in tertiary hospitals, quality improvement measures and comprehensive payment policies, such as clinical pathways and prospective payment methods, should be considered.

\section{Author affiliations}

${ }^{1}$ China Center for Health Development Studies, Peking University, Beijing, China ${ }^{2}$ School of Management, Beijing University of Chinese Medicine, Beijing, China ${ }^{3}$ School of Economics and School of Management, Tianjin Normal University, Tianjin, China

${ }^{4}$ Research Institute for International Strategies, Guangdong University of Foreign Studies, Guangzhou, China

${ }^{5}$ TOP Education Institute, Sydney, New South Wales, Australia

${ }^{6}$ Newcastle Business School, University of Newcastle, Newcastle, Callaghan, Australia

Contributors DZ, XS and PH participated in the study concept and design; DZ and $\mathrm{PH}$ performed the statistical analysis and drafted the first version of the manuscript; QB and SN performed critical revision of article for important intellectual content; all authors contributed to the data interpretation.

Funding This paper was supported by Peking University's Start-up Fund (No. BMU2018YJ004).

Competing interests None declared.

Patient consent for publication Not required.

Provenance and peer review Not commissioned; externally peer reviewed.

Data availability statement Data may be obtained from a third party and are not publicly available.

Open access This is an open access article distributed in accordance with the Creative Commons Attribution Non Commercial (CC BY-NC 4.0) license, which permits others to distribute, remix, adapt, build upon this work non-commercially, and license their derivative works on different terms, provided the original work is properly cited, appropriate credit is given, any changes made indicated, and the use is non-commercial. See: http://creativecommons.org/licenses/by-nc/4.0/.

\section{REFERENCES}

1. Central Committee of the Communist Party of China,Stata Council. Opinions of the CPC central Committee and the state Council on deepening the health care system reform, 2009. Available: http:// www.gov.cn/jrzg/2009-04/06/content_1278721.htm

2. Liu X, Liu Y, Chen N. The Chinese experience of hospital price regulation. Health Policy Plan 2000;15:157-63.

3. Luk S. The politics of drug price control policy in China: regulation, deregulation and Re-regulation. Journal of Contemporary East Asia Studies 2015;4:41-54.

4. Guo Z, Guan X, Shi L. The impacts of implementation of national essential medicines policies on primary healthcare institutions: a cross-sectional study in China. BMC Health Serv Res 2017;17:723.

5. Beijing Municipal Government. Implementationplan for comprehensive reform on separating drugsales from hospital revenues 2017 .

6. Yip W, Hsiao W. China's health care reform: a tentative assessment. China Econ Rev 2009;20:613-9.

7. Blumenthal D, Hsiao W. Privatization and its discontents - the evolving Chinese health care system. N Engl J Med 2005;353:1165-70.

8. Sun Q, Santoro MA, Meng Q, et al. Pharmaceutical policy in China. Health Aff 2008;27:1042-50. 
9. Yang $C$, Shen $Q$, Cai W, et al. Impact of the zero-markup drug policy on hospitalisation expenditure in Western rural China: an interrupted time series analysis. Trop Med Int Health 2017;22:180-6.

10. Yip WC-M, Hsiao WC, Chen W, et al. Early appraisal of China's huge and complex health-care reforms. Lancet 2012;379:833-42.

11. Wei X, Zou G, Zhang H, et al. Implementation of the Chinese national microscopy centre policy: health facility survey in Shandong Province. Trop Med Int Health 2011;16:847-53.

12. Hu R, Liao Y, Du Z, et al. Types of health care facilities and the quality of primary care: a study of characteristics and experiences of Chinese patients in Guangdong Province, China. BMC Health Serv Res 2016;16:335.

13. Wang L, Suo S, Li J, et al. An investigation into traditional Chinese medicine hospitals in China: development trend and medical service innovation. Int J Health Policy Manag 2016;6:19-25.

14. State Council General Office. The state council general office opinions on overall pilot reform in the county level public hospital (Guo Ban Fa[2012] No.33), 2012. Available: http://www.gov.cn/xxgk/ pub/govpublic/mrlm/201206/t20120614_65217.html [Accessed 10 Aug 2018].

15. McCollum R, Chen L, ChenXiang $T$, et al. Experiences with primary healthcare in Fuzhou, urban China, in the context of health sector reform: a mixed methods study. Int $J$ Health Plann Manage 2014;29:e107-26.

16. Ding L, Wu J. The impact of China's national essential medicine policy and its implications for urban outpatients: a multivariate Difference-in-Differences study. Value Health 2017;20:412-9.

17. National Health Commission. China health and family planning Yearbook. China Union Medical University Press, 2017.

18. World Bank. Deepening health reform in China: building highquality and value-based service delivery - policy summary (English). Washington, D.C: World Bank Group, 2016.

19. Fu H, Li L, Yip W. Intended and unintended impacts of price changes for drugs and medical services: evidence from China. Soc Sci Med 2018;211:114-22.

20. Liu X, Xu J, Yuan B, et al. Containing medical expenditure: lessons from reform of Beijing public hospitals. BMJ 2019;30.

21. Jia-hua L, Yi L, Zhi-shui C, et al. Impact of separating drug sales from medical services reform on Beijing cancer Hospital from the perspective of medical insurance data. Chinese Journal of Health Policy 2017;10:15-21.

22. Yi-zhang $L$, Jian $Z$. The impact of separating drug sales from medical services reform on the operation of tertiary General Hospital in
Beijing: case study of R Hospital. Chinese Journal of Health Policy 2017;10:22-6.

23. Shu-duo Z, Yu Z, Shuo Y, et al. The comprehensive reform of separating drug sales from medical services and its impact on outpatients and emergency medical flow in Beijing. Chinese Journal of Health Policy 2018;11:37-41.

24. Yu Z, Shu-duo Z, Shuo Y, et al. The impact of separating drug sales from medical services reform on mechanism of controlling outpatient and emergency expenses in Beijing. Chinese Journal of Health Policy 2017;10:9-14.

25. Yi H, Miller G, Zhang L, et al. Intended and unintended consequences of China's zero markup drug policy. Health Aff 2015;34:1391-8.

26. Lopez Bernal J, Cummins S, Gasparrini A. Interrupted time series regression for the evaluation of public health interventions: a tutorial. Int J Epidemiol 2016;12:dyw098.

27. Wagner AK, Soumerai SB, Zhang F, et al. Segmented regression analysis of interrupted time series studies in medication use research. J Clin Pharm Ther 2002;27:299-309.

28. Gao H, Harrison DA, Parry GJ, et al. The impact of the introduction of critical care outreach services in England: a multicentre interrupted time-series analysis. Crit Care 2007;11.

29. Gerrish E. The effect of the child support performance and incentive act of 1998 on Rewarded and Unrewarded performance goals. $J$ Policy Anal Manage 2017;36:65-96.

30. Wooldridge JM. Introductory econometrics: a modern approach. 6th edn. Boston, MA: Cengage Learning, 2016

31. Bhaskaran K, Gasparrini A, Hajat S, et al. Time series regression studies in environmental epidemiology. Int $\mathrm{J}$ Epidemiol 2013;42:1187-95.

32. Autor David $\mathrm{H}$. Outsourcing at will: the contribution of unjust dismissal doctrine to the growth of employment outsourcing.

33. Bertrand M, Duflo E, Mullainathan S. How much should we trust Difference-in-Differences estimates?

34. Donald SG, Lang K. Inference with Difference-in-Differences and other panel data. Rev Econ Stat 2007;89:221-33.

35. Ellis RP, Martins B, Zhu W. Health care demand elasticities by type of service. J Health Econ 2017;55:232-43.

36. Guan X, Yang M, Man C, et al. The effect of the implementation of low price medicine policy on medicine price in China: a retrospective study. Int J Health Plann Manage 2018;33:e798-806.

37. McGuire TG, Pauly MV. Physician response to fee changes with multiple payers. J Health Econ 1991;10:385-410. 